\title{
ANÁLISE DA INDÚSTRIA MADEIREIRA NA AMAZÔNIA: GESTÃO, USO E ARMAZENAMENTO DE RESÍDUOS*
}

\section{Wilson Fernandes Ramos}

Mestre em Ciências Ambientais pela Universidade Federal do Pará (UFPA) do Programa de Pós-Graduação de Ciências Ambientais (PPGCA)/Empresa Brasileira de Pesquisa Agropecuária (EMBRAPA)/ Museu Paraense Emílio Goeldi (MPEG) - Belém (PA), Brasil.

\section{Maria de Lourdes}

Pinheiro Ruivo

Pesquisadora do Museu Paraense Emílio Goeldi (MPEG), Coordenação de Ciências da Terra e Ecologia (CCTE), bolsista de Produtividade em Pesquisa 2 do Conselho Nacional de Desenvolvimento Científico e Tecnológico (CNPq) - Belém (PA), Brasil.

Mario Augusto

Gonçalves Jardim

Pesquisador do Museu Paraense Emílio Goeldi (MPEG), Coordenação de Botânica (CBO) - Belém (PA), Brasil.

\section{Roberto Porro}

Pesquisador Embrapa Amazônia Oriental. Coordenação de Ciências Florestais - Belém (PA), Brasil.

\section{Rosecélia Moreira} da Silva Castro

Bolsista Pós-Doutorado da Coordenação de Aperfeiçoamento de Pessoal de Nível Superior (CAPES) pela UFPA, do Programa de Pós-Graduação em Ciências em Ambientais/PPGCA/ MPEG/EMBRAPA - Belém (PA), Brasil.

\section{Larissa Melo de Sousa}

Mestra em Ciências Ambientais pela UFPA do Programa de Pós-Graduação de Ciências Ambientais/PPGCA/ EMBRAPA/MPEG. Departamento de Geociências (DG) - Belém (PA), Brasil.

*Este trabalho é parte da dissertação do primeiro autor.

\section{Endereço para correspondência:}

Wilson Fernandes RamosUniversidade Federal do Pará - 66075110-Belém (PA), Brasil-E-mail: wilson.f.ramos18@hotmail.com

Recebido: 08/06/2015

Aceito: 27/01/2017

\section{RESUMO}

Apesar da importância econômica e social da indústria madeireira, ainda são poucos os estudos envolvendo sua cadeia produtiva na Amazônia, principalmente com enfoque na gestão dos resíduos provenientes da produção. Muitos deles estão nos bancos de dados dos órgãos públicos e privados ligados à problemática ambiental e madeireira. $\mathrm{O}$ objetivo deste trabalho foi realizar, a partir de levantamento de dados, a sistematização e a análise das informações, de forma a auxiliar na gestão da matéria-prima e dos resíduos resultantes do processo de industrialização da madeira, e contribuir para o conhecimento sobre o estado atual da gestão dos resíduos provenientes das indústrias. Também é proposta uma metodologia que permite estudos sistemáticos, para contribuir com os órgãos públicos e privados ligados à problemática ambiental e madeireira, com o objetivo de facilitar a realização de outros estudos com a mesma temática. A indústria madeireira apresentou um baixo rendimento operacional e, por conseguinte, uma alta geração de resíduos que, caso não dispostos ou aproveitados de maneira correta, trazem problemas ambientais (como a contaminação de rios, solos e ar) e sociais (como problemas respiratórios e proliferação de vetores de doenças que podem afetar a população ao redor dessas indústrias).

Palavras-chave: indústria madeireira; resíduos sólidos; Amazônia.

\section{ABSTRACT}

Despite the economic and social importance of the timber industry, there are still few studies involving its production chain in the Amazon, mainly focusing on the management of waste from production. Much of this information is in the databases of public and private agencies related to environmental issues and timber. The systematization and analysis of these data is important to assist in management of raw materials and waste resulting from the wood industrialization process, in order to contribute to the knowledge of the current state of waste management from the industries. It's was also proposed a methodology that will allow systematic studies on the subject, contributing with public and private institutions linked to environmental issues and timber and can thus contribute to the public policy actions aimed at this sector. The logging industry has shown a low operating income and, consequently, a high generation of waste which, if not disposed or used correctly, may cause environmental problems (such as rivers, soil and air contamination) and social problems (such as respiratory problems and the proliferation of vectors of diseases that can affect the population around these industries).

Keywords: timber industry; wood waste; social and environmental problems; Amazon. 


\section{INTRODUÇÃO}

A indústria madeireira é um dos setores mais importantes em termos mundiais e se destaca por ser um setor da economia brasileira de grande representatividade, haja vista a geração de renda, tributos, divisas, empregos (NUNES; MELO; TEIXEIRA, 2012). No entanto, também é fonte de um forte passivo ambiental e de saúde pública. Essa indústria consome a biodiversidade de nossas florestas, pois utiliza a madeira, uma das principais matérias-primas de inúmeros segmentos da economia, como a construção civil e a fabricação de móveis (VIDOR et al., 2010), hoje muito demandada pelo crescimento do consumo tanto nacional quanto internacional. Assim, apesar de ser uma importante fonte de receita e emprego para a Região Amazônica, e mesmo para o restante do Brasil, pouco se inova em produção, armazenamento e gestão de resíduos oriundos do processo industrial, o que tem se tornado um problema de saúde pública e preservação ambiental.

O Brasil tem mais de $61 \%$ do território recoberto pela Amazônia legal, sendo $49 \%$ pelo Bioma Amazônia, o que o coloca entre os principais países florestais do planeta (CASTRO \& SILVA, 2007; PEREIRA et al., 2010; RIVERO et al., 2011). Nesse sentido, a Amazônia brasileira responde por mais de $90 \%$ da produção florestal de áreas naturais do Brasil (CASTRO \& SILVA, 2007): aproximadamente 14 milhões de $\mathrm{m}^{3}$ de madeira em tora são extraídos de seu território. Apesar de todo o esforço das legislações federal e estadual, a maior parte dessa retirada ainda é feita de forma ilegal.

Na Amazônia legal, devido à falta de investimentos em equipamentos, em capacitação e em matérias-primas de qualidade, o rendimento operacional (o qual é a relação entre o volume de madeira serrada que se obtém e o volume de toras que foram usadas para o processamento) é, em média, de 41\% (SFB \& IMAZON, 2010). Com um rendimento operacional tão baixo, a produção de resíduos madeireiros se torna um entrave para o desenvolvimento sustentável dessas indústrias e causa inúmeros problemas socioambientais.

Segundo a Associação Brasileira de Normas Técnicas (ABNT, 2004), o resíduo sólido pode ser entendido como todo resíduo nos estados sólido e semissólido que resulte de atividades de origem industrial, doméstica, hospitalar, comercial, agrícola, de serviços e de varrição. Essa norma ainda classifica os resíduos em: classe I, perigosos, e classe II, não perigosos (dividida em IIA-não inertes e IIB-inertes). Nesse sentido, os resíduos da indústria madeireira, em sua maioria, são considerados "sólidos", "não perigosos" e "não inertes"; porém, apresentam as características de combustibilidade e degradabilidade, podendo causar incêndios acidentais ou proliferação de insetos (BRITO \& CUNHA, 2009).

Os resíduos madeireiros, quando gerados em grande quantidade e armazenados de maneira incorreta, levam a sérios riscos socioambientais, como a contaminação ambiental do ar, dos cursos d'água e do solo, riscos à saúde pública e do trabalhador, além do desperdício de matéria-prima e energia (RIUL \& RIBEIRO, 2012). Por isso, a sua reutilização ou reciclagem são práticas de gerenciamento que deveriam ser conduzias por todas as empresas que geram esse resíduo (LEEUWESTEIN \& MONTEIRO, 2000), o que nem sempre ocorre, muitas vezes por falta de conhecimento dos gestores e trabalhadores ou em decorrência da deficiente fiscalização do poder público.

Nessa perspectiva, uma das formas de diminuir a quantidade de resíduos de madeira, principalmente na Região Amazônica, é por meio da queima a céu aberto. Entretanto, essa prática contribui para a geração de $\mathrm{CO}_{2}$, exercendo influência sobre a mudança climática do planeta, além de problemas de saúde pública, como os respiratórios (FONTES, 1994; TUOTO, 2009) - tanto nos trabalhadores como na comunidade no entorno dos focos de queima.

No entanto, os resíduos madeireiros, quando gerenciados de forma correta, podem trazer benefícios econômicos e ambientais para toda a sociedade. Algumas formas ou metodologias de reciclagem já estão relatadas na literatura. As principais alternativas para a reciclagem ou a reutilização dos resíduos de madeira recomendadas são: compostagem, geração de energia, produção de painéis, fabricação de pequenos artefatos de madeira e utilização como condicionantes do solo (GOMES \& SAMPAIO, 2004; ZENID, 2009; SZABÓ JUNIOR, 2010; CIRIBELLI \& FERNANDES, 2011; RUIVO et al., 2007; MONTEIRO et al., 2010).

Apesar de a legislação ambiental brasileira ser uma das mais avançadas do mundo, e existirem também 
leis estaduais, a sua aplicação é dificultada pela baixa qualidade da fiscalização, seja pelo número reduzido de fiscais, seja pela grande quantidade de indústrias não legalizadas, que apresentam a dicotomia de terem notória importância econômica, porém serem nocivas e predatórias para o ecossistema amazônico; seus principais problemas consistem na grande geração de resíduos e, consequentemente, na dificuldade de armazenamento e aproveitamento de tais componentes.
Também dificultam a gestão dos resíduos a falta de conhecimento sistêmico e a falta de um método de análise das informações sobre as empresas madeireiras e seus resíduos gerados, fatores que poderiam facilitar os estudos futuros. É nesse contexto que se insere o presente artigo, que objetiva contribuir para o conhecimento e a análise da questão socioambiental da geração de resíduos provenientes da indústria madeireira na Amazônia.

\section{MATERIAIS E MÉTODOS}

Foi realizado um diagnóstico socioambiental da geração e do aproveitamento dos resíduos da indústria madeireira, identificando as espécies florestais utilizadas, sua origem, a quantidade de resíduos produzidos nessa atividade, se existem ações de reciclagem ou reaproveitamento do resíduo, bem como a influência da atividade nas comunidades próximas e no meio ambiente. A investigação é importante para se entender a real influência desses resíduos. Este estudo levantou dados sobre empresas do setor madeireiro na Região Metropolitana de Belém (RMB). Após o devido contato com os proprietários, donos ou responsáveis técnicos dessas empresas, foi feita uma visita técnica para a realização de entrevista com um responsável pela atividade madeireira. A entrevista, semiestruturada, buscou informações referentes à geração, aos tipos e à destinação desses resíduos. A população que vive próxima dessas indústrias foi visitada com o objetivo de saber se a atividade da empresa afeta o bem-estar dos moradores (por exemplo, causando problemas de saúde, como dificuldade de respirar, alergias de pele e intestinais, entre outros).

A indústria madeireira é um dos setores mais importantes da economia mundial, em razão de a madeira ser uma das principais matérias-primas de inúmeros segmentos da economia, como a construção civil e a fabricação de móveis (VIDOR et al., 2010). Ademais, essa indústria apresenta grande representatividade na economia brasileira desde a colonização portuguesa até a atualidade (NUNES; MELO; TEIXEIRA, 2012).

Essa indústria pode ser entendida como "a indústria do ramo florestal que processa a madeira, em estado de madeira-prima para a produção de madeira roliça, madeira serrada, compostos laminados, compostos particulados, lenha e carvão" (LIMA \& SILVA, 2005). Parale- lamente, Biasi e Rocha (2007) explicam que a indústria madeireira é baseada no processamento da madeira, embora algumas vezes seja responsável pelo plantio e o beneficiamento do produto, sendo o segmento do setor florestal brasileiro com maior participação no mercado externo. Nesse sentido, apesar de toda a legislação florestal brasileira a favor de preservá-la, o desflorestamento da floresta ainda é grande e o reflorestamento de espécies vegetais nas áreas alteradas é pouco expressivo.

A cadeia produtiva mostra como, a partir da matéria-prima "árvore", ainda é possível aproveitar inúmeros subprodutos e que, apesar do avanço da tecnologia e da inovação científica, tal material ainda não pode ser substituído por alternativas que sejam de fato aceitas e consumidas pelo mercado. Assim, é compreensível que a pressão sob a floresta não tenha diminuído, apesar do esforço governamental e de inúmeros programas que tentam adotar uma alternativa à exploração da Floresta Amazônica, como, por exemplo, a Redução de Emissões por Desmatamento e Degradação Florestal (REDD) (AMARANTE \& RUIVO, 2013).

A floresta Amazônica responde por mais de $90 \%$ da produção florestal de áreas naturais do Brasil (CASTRO \& SILVA, 2007) e ocupa aproximadamente $49 \%$ de todo o território brasileiro (PEREIRA et al., 2010). Sua importância é tanto socioambiental quanto econômica. Segundo Uhl et al. (1991), o estoque madeireiro da Amazônia é suficiente para suprir a demanda mundial por cerca de um século, sendo estimado entre 40 e 60 bilhões de $\mathrm{m}^{3}$ de toras.

O setor madeireiro na Amazônia legal pode ser dividido em fronteiras de exploração, as quais são classificadas conforme sua tipologia florestal, a idade da fronteira, a condição de acesso e o meio de locomoção (VERís- 
SIMO; LIMA; LENTINI, 2002; LENTINI et al., 2005). A esse respeito, existem na Região Amazônica quatro fronteiras: antigas (mais de 30 anos, localizadas ao sul e a leste da Amazônia ); intermediárias (10 a 30 anos, situadas em torno de Porto Velho-RO e Rio Branco-AC; novas (menos de 10 anos, destacando-se o oeste do Pará); e, por fim, a estuarina (que abrange as ilhas dos Estados do Pará, principalmente, a de Marajó e Amapá, onde predominam florestas de várzea; a exploração madeireira ocorre de forma seletiva e esporádica desde o século XVII).

Essas fronteiras de exploração apresentam inúmeros polos madeireiros, os quais podem ser entendidos como municípios cujo volume de madeira em tora extraído e consumido por ano é igual ou superior a $100 \mathrm{mil} \mathrm{m}^{3}$ (VERÍSSIMO; LIMA; LENTINI, 2002).

Na Amazônia legal, de acordo com o Serviço Florestal Brasileiro e o Instituto do Homem e Meio Ambiente da Amazônia (SFB \& IMAZON, 2010), existem aproximadamente 71 polos madeireiros (30 apenas no Estado do Pará). São cerca de 2.227 indústrias desse setor na região. Outro ponto importante é a receita bruta, que chega a US\$ 2,4 bilhões. As indústrias madeireiras, situadas na Amazônia legal, geraram aproximadamente 204 mil empregos em 2009; desses, quase 67 mil foram diretos, os quais ocorrem na fase de exploração florestal e processamento da madeira; e 137 mil foram indiretos. Assim, a importância da indústria madeireira para a economia da região é expressiva, principalmente para o Pará, em que essa indústria e a de mineração são as principais responsáveis pelo produto interno bruto (PIB). Aproximadamente $44 \%$ da receita bruta da Amazônia legal para essa atividade vem do Pará, que apresenta o maior número de indústrias, com cerca de $47 \%$ de toda a região (Tabela 1 ).

A indústria madeireira consegue produzir $100 \%$ a mais de empregos indiretos. Em 2009, o Pará gerou cerca de $45 \%$ do total de empregos na região; assim, é o Estado que mais emprega no setor, com quase o dobro de novos postos de trabalho em relação ao segundo Estado que mais gera emprego, Mato Grosso. Isso mostra a importância socioeconômica dessa atividade. Contudo, a qualidade desse emprego é discutível, pois nem sempre exige muita escolaridade, já que essa indústria não possui muitas inovações tecnológicas e não prima pela preservação ambiental.

Esses números comprovam a relevância do Estado para o setor madeireiro da região. Nesse contexto, os municípios da RMB - composta pela capital Belém e pelos municípios de Ananindeua, Benevides, Marituba e Santa Bárbara do Pará - fazem parte de um desses polos com um consumo superior a $697 \mathrm{mil} \mathrm{m}^{3}$ toras por ano, gerando, assim, aproximadamente $13 \mathrm{mil} \mathrm{em}$ pregos diretos e indiretos em 2009 (SFB \& IMAZON, 2010). A RMB apresenta, de acordo com dados levantados junto à Secretária Estadual do Meio Ambiente

Tabela 1 - Produção e receita da indústria madeireira na Amazônia.

\begin{tabular}{|c|c|c|c|c|c|c|}
\hline \multirow{2}{*}{ Estado } & \multirow{2}{*}{$\begin{array}{l}\text { Número de polos } \\
\text { madeireiros }\end{array}$} & \multirow{2}{*}{$\begin{array}{l}\text { Número de } \\
\text { indústrias }\end{array}$} & \multirow{2}{*}{$\begin{array}{l}\text { Receita bruta } \\
\text { (US\$ milhões) }^{3}\end{array}$} & \multicolumn{3}{|c|}{$\begin{array}{c}\text { Empregos gerados pela indústria } \\
\text { madeireira }(2009)^{4}\end{array}$} \\
\hline & & & & Diretos & Indiretos & Total \\
\hline Acre & 1 & 24 & 91,4 & 1.518 & 3.123 & 4.641 \\
\hline Amapá & 1 & 48 & 16,1 & 496 & 1.020 & 1.516 \\
\hline Amazonas & 3 & 58 & 57,9 & 2.135 & 4.390 & 6.525 \\
\hline Maranhão & 1 & 54 & 29,7 & 1.301 & 2.675 & 3.976 \\
\hline Mato Grosso & 20 & 592 & 803,2 & 18.624 & 38.308 & 56.932 \\
\hline Pará & 30 & 1.067 & $1.094,2$ & 30.235 & 62.189 & 92.424 \\
\hline Rondônia & 14 & 346 & 358,6 & 11.393 & 23.433 & 34.826 \\
\hline Roraima & 1 & 37 & 31,5 & 937 & 1.928 & 2.865 \\
\hline Amazônia legal ${ }^{1}$ & 71 & 2.226 & 2482,6 & 66.639 & 137.066 & 203.705 \\
\hline
\end{tabular}

${ }^{1} \mathrm{Não}$ inclui o Tocantins, pois o Estado não possuía polos madeireiros em 2009. ${ }^{2}$ Incluindo as microsserrarias. ${ }^{3}$ Câmbio médio de 2009: US\$ 1,00/ $\mathrm{R} \$ 1,99$ (BCB, 2010). ${ }^{4}$ Cada emprego direto gerou, em média, 2,06 empregos indiretos. 
(SEMA), 116 empresas registradas com status ativo. Nesse montante estão incluídas serrarias, beneficiadoras, laminadoras e movelarias.

A maioria dessas empresas fica localizada no município de Belém (42), seguido por Ananindeua (24), Benevides (23), Santa Barbara do Pará (12), Marituba (10) e Santa Isabel do Pará (5). Ananindeua, além de ser a segunda cidade em habitantes da RMB, é um importante polo industrial e não só da indústria madeireira. $O$ montante de empresas situadas apenas na RMB, mostrando como o polo madeireiro de Belém, que apresenta $36 \%$ das empresas da região, é relevante tanto para o Estado quanto para a Região Amazônica. Contudo, esses números devem ser bem maiores, visto que só foram quantificados as empresas registradas na SEMA do Pará e com status ativo, ou seja, empresas que não estão registradas ou que estão com o registro suspenso ou cancela- do não foram quantificadas. Nos últimos anos, o setor madeireiro paraense vem apresentando uma dinâmica de redução do volume produzido, enquanto o valor de produção caminha em sentido oposto (Tabela 2), provocando um crescimento que gera um movimento de elevação dos preços (SILVA \& MARQUES, 2012).

As informações acima mostram uma expressiva redução nas exportações e no valor bruto da madeira. Essa redução expressiva possui três causas principais: produtos substitutos, aumento da fiscalização e crise econômica (SFB \& IMAZON, 2010). A legislação ambiental e a fiscalização inovadora, por intermédio de sensores remotos e em tempo real levado pelo Ministério do Meio Ambiente (MMA) e Instituto Nacional de Pesquisas Espaciais (INPE), têm surtido efeito, e é cada vez mais comum a apreensão de madeira retirada de forma ilegal da floresta.

\section{RESULTADOS E DISCUSSÃO}

Os resíduos da indústria madeireira podem ser considerados sólidos e inertes segundo a ABNT (2004) e atualmente, segundo a Lei $n^{\circ} 12.305$, de 2 de agosto de 2010 (BRASIL, 2010), que institui a Política Nacional de Resíduos Sólidos (PNRS), eles podem ser definidos como: material, substância, objeto ou bem descartado resultante de atividades humanas em sociedade cuja destinação final procede, se propõe a proceder ou está obrigada a proceder a sua destinação de forma racional, nos estados sólido ou semissólido, bem como gases contidos em recipientes e líquidos cujas particularidades tornem inviável o seu lançamento na rede pública de esgoto ou em corpos d'água, ou exijam para isso soluções técnicas ou economicamente inviáveis diante da melhor tecnologia disponível. A partir dessa legislação, todo resíduo deve ser tratado e acondicionado conforme sua necessidade e de forma a impactar o mínimo possível o ambiente circundante, que inclui também a comunidade ou a sociedade.

A importância econômica do setor madeireiro é incontestável. Com isso, há uma grande preocupação em relação aos resíduos considerados sólidos, normalmente de composição orgânica e de origem industrial, produzidos por essa indústria (PEREIRA et al., 2010). Nesse contex-

Tabela 2 - Evolução da produção madeireira no Pará de 2001 a 2009.

\begin{tabular}{|l|c|c|c|}
\hline Ano & $\begin{array}{c}\text { Quantidade produzida } \\
\text { de madeira em tora }\left(\mathbf{m}^{\mathbf{3}}\right)\end{array}$ & $\begin{array}{c}\text { Valor da produção de } \\
\text { madeira em tora (1.000 R\$) }\end{array}$ & Preço do $\mathbf{m}^{\mathbf{3}}$ em R\$ \\
\hline 2001 & 10.645 .334 & 580.160 & 54,50 \\
\hline 2002 & 10.209 .043 & 719.106 & 70,44 \\
\hline 2003 & 10.844 .175 & 834.742 & 76,98 \\
\hline 2004 & 10.601 .633 & 946.393 & 89,27 \\
\hline 2005 & 9.935 .853 & 958.045 & 96,42 \\
\hline 2006 & 9.506 .602 & 1.008 .626 & 106,10 \\
\hline 2008 & 90.990 .150 & 1.036 .289 & 114,00 \\
\hline 2009 & 7.618 .913 & 1.062 .567 & 139,46 \\
\hline
\end{tabular}


to, estima-se que, no Brasil, sejam gerados aproximadamente 30 milhões de toneladas de resíduos de madeira anualmente; essa estimativa abrange a atividade de poda de árvores em áreas urbanas, a construção civil e a indústria madeireira (Tabela 3). Assim, a indústria madeireira gera quase $91 \%$ de todo o resíduo madeireiro do Brasil, seguido pela poda de árvores urbanas, a qual contribui com $6 \%$ dos resíduos de madeira gerados, e pela construção civil, com apenas 3\% dos resíduos madeireiros produzidos no ano de 2009.

O resíduo gerado pela indústria madeireira é um material que, se não disposto de forma correta, pode constituir uma ameaça para o meio ambiente. Esse material pode ser utilizado de maneira alternativa para aumentar as receitas de algumas empresas madeireiras (FRANCESCHIN, 2004). Essas indústrias têm a maioria dos seus resíduos gerada no processamento primário, ainda que essa fração percentual modifique em função de determinados fatores, por exemplo, o tipo de processo ou o maquinário utilizado (FINOTTI et al., 2006).

No caso da madeira de reflorestamento, as perdas no desdobro e nos cortes de resserra chegam, respectivamente, a 20 e $40 \%$ do volume das toras que sofreram processamento. Porém, na Região Amazônica, o processamento da madeira nativa chega a perdas de 59\% (SFB \& IMAZON, 2010). Com isso, tem-se um rendimento operacional médio das serrarias brasileiras na faixa de 60 a $80 \%$, caracterizando um cenário de baixa tecnologia associado a um mau aproveitamento da madeira em função da grande quantidade de resíduos gerados (CERQUEIRA, 2012; BATISTA; SILVA; CORTELETTI, 2013). Em geral, os resíduos são classificados em três tipos distintos: serragem (resíduo originado da operação de serras, encontrado em todos os tipos de indústria); cepilho (resíduo gerado pelas plainas nas instalações de serraria/beneficiamento e beneficiadora); lenha (resíduo de maiores dimensões, gerado na maioria das indústrias desse setor, composto por costaneiras, aparas, refilos, resíduos de topo de tora e restos de lâminas) (FONTES, 1994).

Os principais tipos de resíduos gerados nas empresas do setor madeireiro são: pó, cepilhos, aparas, lenha e varrição de fábrica. Na indústria moveleira, além dos resíduos sólidos de madeira, há a geração de plástico, papel, metal, lixa e líquidos, como solvente de tinta borra de tinta e água de cabine de pintura (LIMA \& SILVA, 2005). A Tabela 4 apresenta o consumo, a produção e as quantidades de resíduos relacionados ao processo produtivo das indústrias madeireiras. No que se refere ao valor de consumo em toras anualmente registrado na Amazônia legal, os Estados do Pará, de Mato Grosso e de Rondônia consomem, juntos, cerca de $90 \%$ de madeira em tora da região. Esses Estados também são os que apresentam a maior produção de madeira processada.

Nesse contexto, o Estado do Pará lidera os índices de consumo, produção e geração de resíduos, com cerca de 4 milhões de $\mathrm{m}^{3}$ de resíduos madeireiros gerados em 2009. Em seguida, os Estados de Mato Grosso e de Rondônia aparecem com uma quantidade 2,2 e 1,25 milhões, respectivamente. Com o menor processamento de madeira e, por conseguinte, a menor geração de resíduos, encontram-se os Estados do Amapá e de Roraima.

Nesse mesmo período, a Amazônia legal gerou mais de 8 milhões de $\mathrm{m}^{3}$ de resíduos. A destinação desses resíduos na Amazônia legal é variada e, de acordo com SFB e Imazon (2010), pode ser feira das seguintes formas: produção de carvão, olarias, cogeração de energia, usos diversos, queima sem destinação energética e sem nenhum aproveitamento (Figura 1).

A destinação mais comum, de acordo com a Figura 1, é por meio do uso diverso que, de acordo com o SFB

Tabela 3 - Estimativa da quantidade de resíduos produzidos no Brasil em 2009.

\begin{tabular}{|l|c|c|}
\hline Fonte geradora & Resíduos de madeira (1.000 t/ano) & $\%$ \\
\hline Indústria madeireira & 27.750 & 90,7 \\
\hline Construção civil & 923 & 3,0 \\
\hline Meio ambiente (poda de árvores urbana) & 1.930 & 6,3 \\
\hline Total & 30.603 & 100,0 \\
\hline
\end{tabular}


e Imazon (2010), inclui: aterros, adubos, lenha, entre outros. Já a produção de carvão vem como a segunda forma de destinação mais encontrada na região, mostrando que o resíduo ainda é utilizado de maneira pouco sustentável. Nesse sentido, há duas possíveis soluções para o tratamento desses resíduos: o processo de reciclagem, que consiste em encontrar utilidade para materiais já utilizados e que não possuem condições de uso (SZABÓ JÚNIOR, 2010), ou a reutilização, que pode ser entendida como o ato de transformar materiais e permitir que eles voltem a ser utilizados, por meio da sua reintrodução no processo produtivo, como um produto novo, semelhante ou não à forma anterior (REVEILLEAU, 2008). Segundo Cassilha et al. (2004), como a maioria dos resíduos da madeira não possui substâncias tóxicas ao meio ambiente, eles podem ser utiliza-

Tabela 4 - Número de empresas, consumo, produção e quantidade de resíduos gerados no Estado do Pará em 2009.

\begin{tabular}{|l|c|c|c|}
\hline Estado & $\begin{array}{c}\text { Consumo anual de toras } \\
\left(\text { milhares } \mathbf{~ m}^{\mathbf{3}}\right)\end{array}$ & $\begin{array}{c}\text { Produção processada total } \\
\left(\text { milhares } \mathbf{~ m}^{\mathbf{3}}\right)\end{array}$ & $\begin{array}{c}\text { Quantidade de resíduos } \\
\text { gerados }\left(\text { milhares } \mathbf{~ m}^{\mathbf{3}}\right)\end{array}$ \\
\hline Acre & 422 & 193 & 229 \\
\hline Amapá & 94 & 41 & 53 \\
\hline Amazonas & 367 & 144 & 223 \\
\hline Maranhão & 254 & 90 & 164 \\
\hline Mato Grosso & 4.004 & 1.795 & 2.209 \\
\hline Pará & 6.599 & 2.550 & 4.049 \\
\hline Rondônia & 2.200 & 950 & 1.250 \\
\hline Roraima & 188 & 70 & 118 \\
\hline Amazônia legal & 14.128 & 5.833 & 8.295 \\
\hline
\end{tabular}

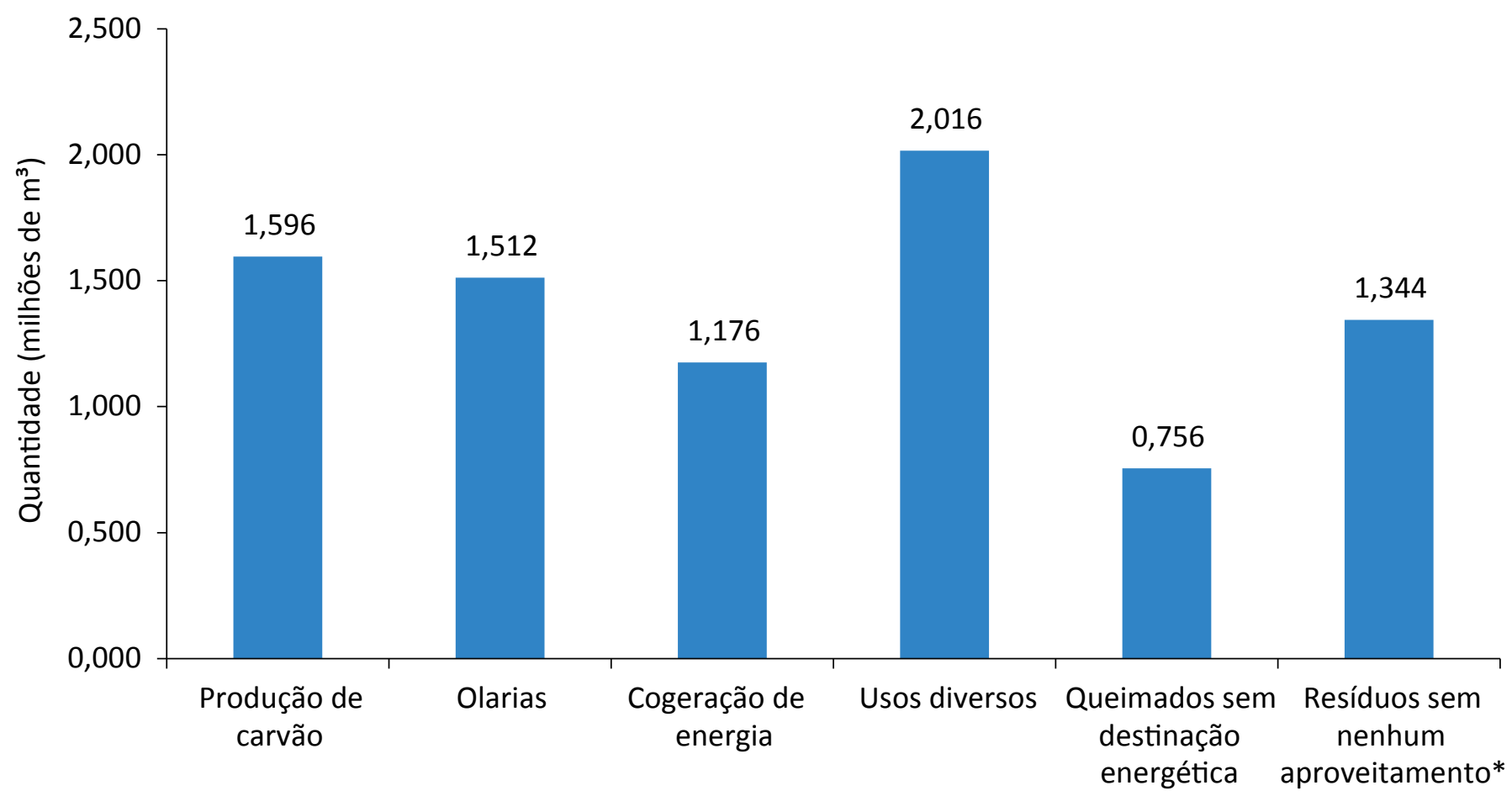

Formas de destinação dos resíduos

Figura 1 - Formas de destinação do resíduo gerado na Amazônia legal em 2009. 
dos, na agricultura, em granjas e currais como forração, com a finalidade de aumentar a retenção de umidade do solo. Dessa forma, as principais alternativas para a reciclagem ou a reutilização dos resíduos de madeira são: compostagem, geração de energia, produção de briquetes, que são matérias com alto poder calorífico, fabricação de pequenos artefatos de madeira, entre outros (GOMES \& SAMPAIO, 2004; GONÇALVES; SARTORI; LEÃO, 2009; ABREU; MENDES; SILVA, 2009; MENDONZA et al., 2010; SILVA, 2011). Atualmente, existem variados usos no aproveitamento dos resíduos produzidos pelas serrarias, especialmente aqueles referentes à elaboração de novos produtos (CEQUEIRO, 2012).

Em relação aos novos usos, a adição de resíduos de madeira ao solo é outra forma de utilização, mostrada por Ruivo et al. (2007) e Monteiro et al. (2010), quando observaram que os solos cobertos com resíduos da indústria madeireira, como lâmina de madeiras apresentaram-se com melhores características químicas e físicas, quando comparados com os solos sem a aplicação dos resíduos. A utilização desses resíduos levou à criação de um ambiente favorável ao melhor desenvolvimento vegetal, em relação à área que não foi recoberta com lâminas de madeira.

Corroborando o exposto, a prática de utilização de resíduos da indústria madeireira como cobertura do solo é vantajosa sob um sistema de reflorestamento com a cultura de paricá (Schizolobium parahyba). Dessa forma, a utilização desses resíduos pode levar a uma nova forma de manejo dos solos amazônicos, além de contribuir para a melhoria da qualidade de vida da população da região (MONTEIRO et al., 2010). O aproveitamento energético de resíduos de madeira que recebem o tratamento adequado pode gerar energia térmica e/ou elétrica (cogeração). Por meio de sua combustão direta ou incineração, essa energia pode ser usada no local de geração (energia térmica) ou em outras regiões, longe do local de geração (BRAND, 2009; BRASIL, 2009).

Lopes (2009) fomenta que, entre os benefícios da utilização de resíduos de madeira, estão: melhoria das condições sociais, por meio da criação de postos de trabalho e do emprego para mão de obra não qualificada; compatibilidade com pequenos investimentos; conservação do meio ambiente em virtude da valorização do resíduo; e incentivo à economia, pois essa técnica agrega valor aos resíduos, proporcionando novas fontes de renda para a cultura local. Entretanto, apesar de haver esforços para a reciclagem das sobras de madeira, principalmente na forma de lenha queimada para a geração de energia elétrica e calor, ou como camade-galinha nas granjas, essas soluções ainda agregam baixo valor ao resíduo (TEIXEIRA, 2005). Contudo, esse mesmo autor coloca duas maneiras de valorizar o resíduo de madeira: quando há a valorização energética e quando a biomassa do resíduo é aproveitada como matéria-prima para fabricação de outros materiais.

Com isso, é possível proporcionar um destino nobre para materiais antes considerados inutilizáveis, como os resíduos de madeira, e, assim, evitar a exploração indevida dos recursos florestais da região para o fornecimento de combustível, nesse caso a lenha, para estabelecimentos consumidores (SILVA et al., 2011). De acordo com o exposto, verifica-se que existem várias destinações para os resíduos de madeira de forma racional, gerando ganhos econômicos e socioambientais. Sendo assim, a Figura 2 apresenta um fluxograma sobre essas destinações.

Inúmeras formas sustentáveis de se aproveitar os resíduos madeireiros tanto dentro quanto fora da indústria foram verificadas; uma das opções defende que eles podem ser vendidos ou reutilizados como matéria-prima na própria empresa para a fabricação de outros produtos. Nessa perspectiva, a preocupação com o gerenciamento correto desses resíduos traz, novamente, a noção de desenvolvimento sustentável. Segundo Brundtland et al. (1991, p. 46), "o desenvolvimento sustentável é aquele que atende às necessidades do presente sem comprometer a possibilidade de as gerações futuras atenderem as suas próprias necessidades". Dessa forma, o aproveitamento correto desses resíduos contribui para o desenvolvimento sustentável das indústrias madeireiras, diminuindo a pressão sobre as florestas e os possíveis danos socioeconômicos.

Segundo Riul e Ribeiro (2012), a gestão inadequada dos resíduos de madeira leva a sérios riscos socioambientais, como a contaminação ambiental do ar pela liberação de gases e fuligem, quando os resíduos são incinerados, dos cursos d'água e do solo, além do desperdício de matéria-prima e energia, danos aos ecossistemas, riscos à saúde pública e do trabalhador. Tais autores assinalam que soluções apropriadas de gestão para os resíduos industriais são fundamentais para a conservação ambiental e a qualidade de vida social; ademais, 
representam práticas racionais e podem melhorar 0 rendimento econômico das empresas.

Uma das formas de diminuir a quantidade de resíduos de madeira, principalmente na Região Amazônica, é por meio da queima a céu aberto. Segundo Lopes (2009), a falta de informação e as dificuldades intrínsecas ao aproveitamento do resíduo madeireiro levam ao seu abandono em aterros e terrenos baldios, à sua queima a céu aberto ou ao seu descarte em cursos d'água. Já especificando o setor moveleiro, o resíduo sólido contribuiu com quase $64 \%$ dos impactos identificados, considerados críticos (LONGO et al., 2013). No Estado do Pará, os resíduos são geralmente utilizados para conversão em energia, por intermédio da queima, e produção de carvão. Esses usos tradicionais promovem o desperdício de recursos naturais e causam impacto ao meio ambiente, pois não levam em conta o potencial econômico e os possíveis danos ambientais desses resíduos (FONTES, 1994). Na realidade, a queima contribui para a geração de $\mathrm{CO}_{2}$, exercendo influência sobre a mudança climática do planeta. Não menos importantes são os problemas de saúde pública que podem ser ocasionados pela queima de resíduos de madeira, pois as cinzas produzidas podem ser facilmente difundidas no ar pelo vento e causar problemas respiratórios em pessoas que residem próximo ao local de eliminação das cinzas (TUOTO, 2009; CHEAH CHEE BAN, 2011).

Outro problema que a disposição incorreta pode trazer é que, por esse resíduo ser composto de celulose

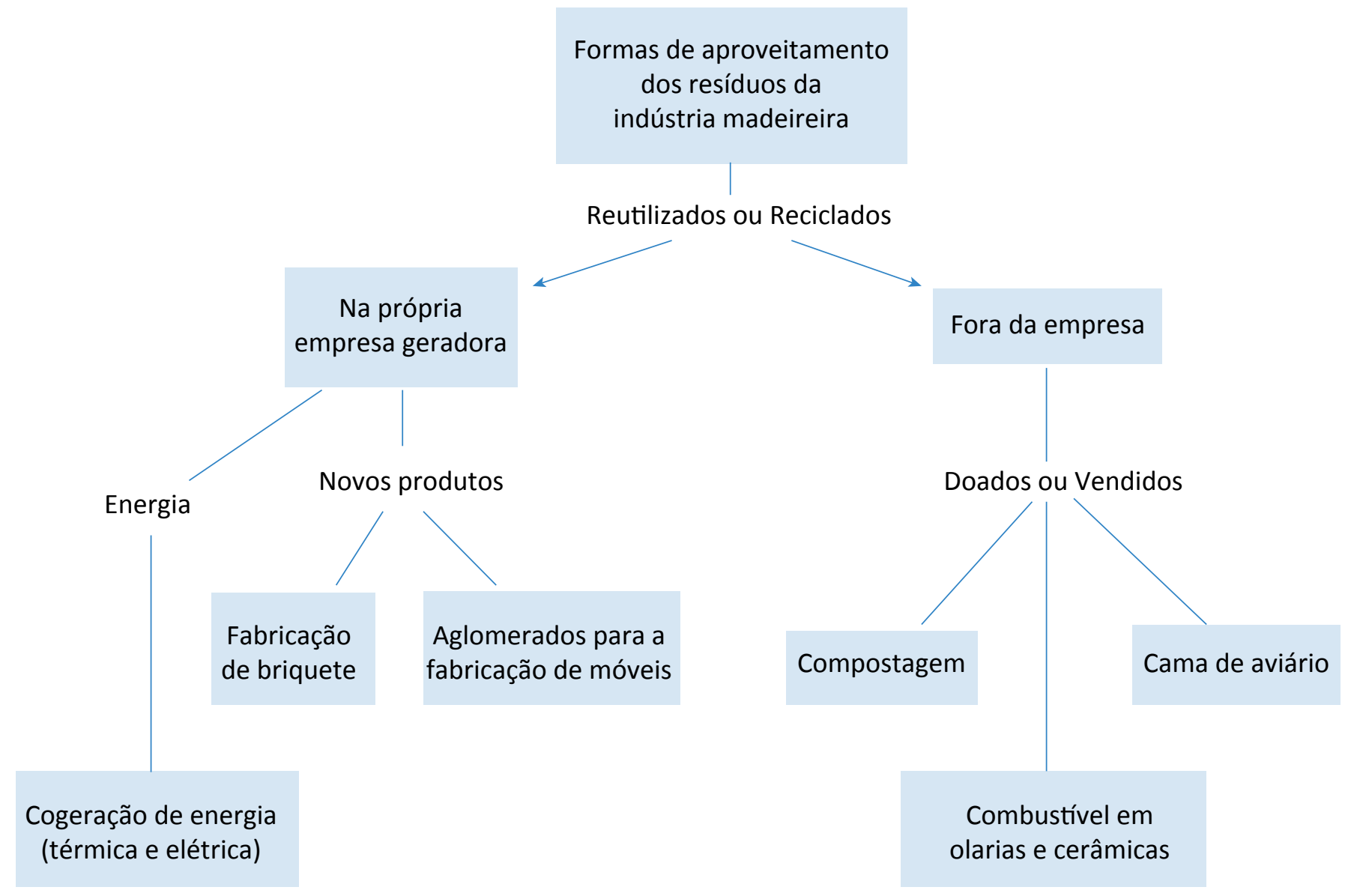

*Inclui o aproveitamento dos resíduos como adubo, em aterros, lenha, entre outros.

Figura 2 - Fluxograma sobre destinação dentro e fora das empresas. 
(fonte de alimento para insetos xilófagos, como térmitas ou cupins), o depósito pode funcionar como foco de atração e disseminação desses insetos, infestando áreas próximas e até mesmo edificações (LELIS, 2001). Os resíduos sólidos de madeira são classificados, de acordo com a ABNT, como "não perigosos" e "não inertes"; com isso, eles apresentam as características de combustibilidade e degradabilidade, podendo causar incêndios acidentais (BRITO \& CUNHA, 2009). Ademais, o resíduo, quando em contato com substâncias tóxicas, pode tornar-se perigoso, contaminando os corpos d'água e o solo e gerando riscos à saúde pública. Um último impacto é a possibilidade de contaminação do solo pela liberação de materiais químicos que foram agregados à madeira durante seu processo de tratamento e beneficiamento (ZENID, 2009; HASAN; GABRIELE; TOWNSEND, 2011).

A madeira é um material que possui baixa resistência à degradação por agentes biológicos, fungos, insetos e intempéries, fatores que degradam a madeira, principalmente quando armazenada em locais úmidos. Com isso, o tratamento da madeira deve ser realizado para prevenir sua deterioração, ampliando, assim, seu tempo de vida útil (CRUZ \& NUNES, 2009).

O tratamento comumente utilizado é o químico, no qual ocorre a fixação de elementos preservativos na madeira, tornando-a mais resistente à ação de fungos e insetos, principalmente se a madeira ficar em contato direto com a água ou com o solo (REVISTA DA MADEIRA, 2008). Segundo Hasan, Gabrieli e Townsend (2011), o conservante mais comumente aplicado na madeira é o arseniato de cobre cromatado (CCA), um produto químico à base de arsênio, cobre e cromo que tem a finalidade de preservar a madeira. Cada um desses três elementos tem potencial negativo de impacto ao meio ambiente e também à saúde das pessoas, variando conforme a concentração. Desse modo, quando esses resíduos com CCA são dispostos no meio ambiente sem tratamento adequado, podem gerar sérios prejuízos à economia, ao ambiente e à saúde pública. Os sais presentes na composição do CCA são bastante tóxicos. Apesar da toxicidade, o CCA ainda é largamente utilizado na indústria madeireira brasileira (HASAN; GABRIELI; TOWNSEND, 2011).
Os impactos ambientais e sociais causados por resíduos industriais variam de acordo com as suas características físico-químicas, sendo necessário um programa diferente de tratamento para cada tipo de resíduo (NAHUZ, 2005).

Com isso, o atual modelo econômico, baseado no consumo exacerbado de bens descartáveis, vem resultando na degradação do solo, no comprometimento dos corpos d'água e mananciais, na intensificação de enchentes, na poluição do ar e na proliferação de vetores de importância sanitária nos centros urbanos (JACOBI \& BESEN, 2001; SILVA \& JOIA, 2008). A partir da análise desses núcleos de pensamento, constata-se que os resíduos podem causar inúmeros problemas não só de cunho ambiental, mas também social e econômico, quando se tornam um passivo ambiental. Dessa forma, a Figura 3 apresenta um fluxograma sobre a problemática relacionada aos resíduos madeireiros.

Nesse sentido, Coronel et al. (2008) explicam que, mais do que nunca, é preciso considerar que todos os problemas no meio ambiente são consequências de outros, ocasionados pelo modo como o homem vê o mundo, suas relações com o poder, com as outras pessoas, com a produção de seus bens e com a geração constante de novas necessidades. Com isso, políticas públicas eficazes seriam uma das formas de atenuar esses problemas; uma dessas é a PNRS (Lei $n^{\circ} 12.305$, de 2 de agosto de 2010), que é um instrumento legal elaborado para minimizar ou mesmo controlar a problemática da geração e do gerenciamento de resíduos sólidos no Brasil e tem como principais objetivos: a proteção da saúde pública e da qualidade ambiental, o que engloba a não geração, a redução, a reutilização, a reciclagem e o tratamento dos resíduos sólidos, bem como a disposição final ambientalmente adequada dos rejeitos. Esses objetivos podem ser muito bem enquadrados na questão da geração e destinação dos resíduos da indústria madeireira. Essa lei, no seu artigo 3ㅇ e inciso $\mathrm{XI}$, define o gerenciamento integrado dos resíduos sólidos como o "conjunto de ações voltadas para a busca de soluções para os resíduos sólidos, de forma a considerar as dimensões política, econômica, ambiental, cultural e social, com controle social e sob a premissa do desenvolvimento sustentável". Com isso, ela não coloca apenas o gerador do resíduo como o principal responsável por encontrar soluções adequa- 
das para o gerenciamento desse rejeito, mas todo o universo de agentes públicos e privados que compartiIham dessa responsabilidade.

Porém, a responsabilidade maior ainda é do gerador desses resíduos. Dessa forma, no artigo 6으 foi colocado o princípio do poluidor-pagador, expondo a responsabilidade do gerador, o qual tem o dever de dar uma destinação racional, que não prejudique o meio ambiente.

Nessa perspectiva, no artigo 80 são expostos os instrumentos da PNRS, entre os quais está a criação de planos de resíduos sólidos nas diferentes esferas do governo. Assim, o poder público, no caso da esfera municipal, fica responsável pela gestão e pelas ações

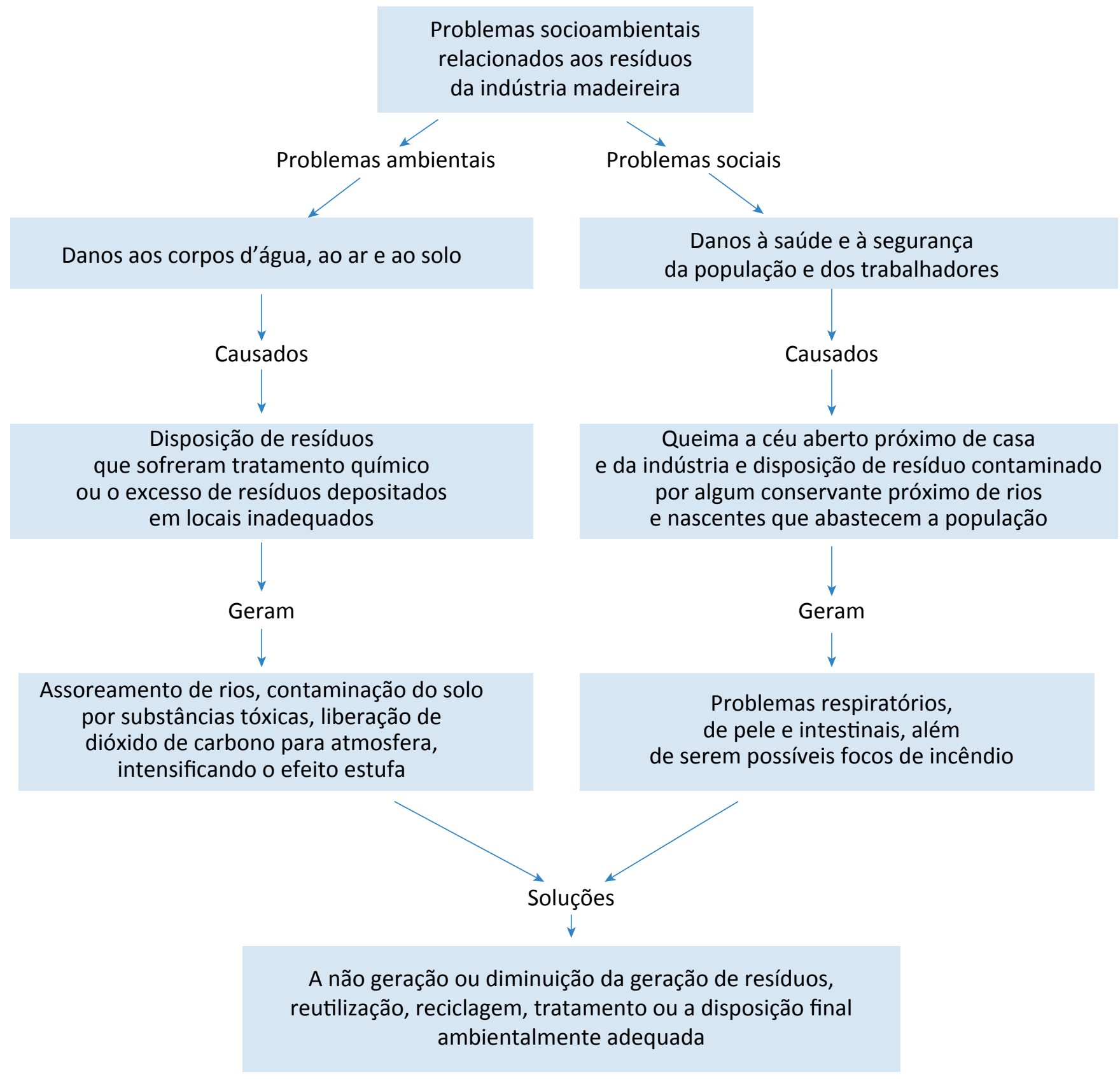

Figura 3 - Problemas sociais e ambientais relacionados aos resíduos sólidos de madeira. 
gerenciadoras relativas às diversas etapas relacionadas aos resíduos sólidos urbanos. Segundo a PNRS, lei que regula os planos municipais de gestão integrada de resíduos (artigo 19), a gestão deve contemplar desde a geração até sua disposição final, após todos os esforços de reutilização e reciclagem terem sido empregados. Paralelamente, os sujeitos geradores de resíduos, no caso as indústrias madeireiras, são obrigados a elaborar um plano de gerenciamento de resíduos sólidos, no qual deve constar, entre outras atribuições, o diagnóstico dos resíduos sólidos gerados ou administrados (contendo a origem, o volume e a caracterização dos resíduos, além dos passivos ambientais a eles relacionados).

A PNRS não é o único instrumento legal que versa sobre o gerenciamento de resíduos sólidos, existem leis e decretos nas diferentes esferas de poder que tratam desse assunto. $O$ Decreto $n^{\circ} 7.404$, de 23 de dezembro de 2010, regulamenta a PNRS, ou seja, estabelece normas para execução dessa política. A Lei Federal $\mathrm{n}^{\circ} 11.445 / 2007$, que estabelece as diretrizes nacionais para o saneamento básico e para a Política Federal de Saneamento Básico, expõe sobre o manejo dos resíduos sólidos realizado de forma adequada à saúde pública e à proteção do meio ambiente. Outro documento importante é a Lei $n^{\circ}$ 9.605, de 12 de fevereiro de 1998, mais conhecida como Lei de Crimes Ambientais, que trata das sanções penais e administrativas contra os que causam, por exemplo, a disposição irregular de resíduos sólidos.

Na esfera estadual, existe, no Pará, a Lei n 7.731, de 20 de setembro de 2013, que dispõe sobre a Política Estadual de Saneamento Básico e também trata da questão do resíduo sólido. Na esfera municipal, a Lei Ordinária no 8.899, de 26 de dezembro de 2011, institui o Plano de Gerenciamento Integrado de Resíduos Sólidos do Município de Belém, dispondo sobre seus princípios, diretrizes e objetivos, para a gestão integrada e o gerenciamento de resíduos sólidos, sob responsabilidade dos geradores e do poder público. Esses são os principais instrumentos normativos que versam sobre gerenciamento de resíduos sólidos, e é neles que os resíduos madeireiros se encaixam. Na realidade, empresários, proprietários dessas indústrias e responsáveis técnicos são obrigados a conhecer o conteúdo dessas leis e decretos, pois o descumprimento desses instrumentos pode causar prejuízos não só socioambientais, mas econômicos para as indústrias madeireiras.

\section{Uma proposta de estudos de diagnóstico para a gestão \\ dos resíduos da indústria madeireira do ponto de vista das ciências ambientais}

O papel da indústria madeireira na Amazônia é incontestavelmente importante, devido, principalmente, à geração de emprego, renda e impostos. Porém, como colocado no presente estudo, essa atividade pode causar sérios problemas socioambientais pela geração exagerada de resíduos madeireiros, devido, muitas vezes, à baixa tecnologia aplicada, à pouca qualificação da mão de obra, à falta de consciência dos empresários para com a questão ambiental e à falta de fiscalização por parte do poder público. Essas premissas apontam que trabalhos envolvendo a área de ciências ambientais em uma visão interdisciplinar se tornam cada vez mais relevantes para se ter uma visão holística da situação atual da problemática do resíduo decorrente de madeireiras, tanto no campo da geração e destinação quanto da questão de problemas socioambientais atrelados a esses resíduos.

Com isso, sugere-se a realização de mais pesquisas sobre essa problemática, por meio de estudos explorató- rios, observacionais e aplicados com visitas in loco para se entender como é gerado e destinado esse resíduo, a opinião dos que moram nas adjacências dessas indústrias, levando em conta a sua percepção sobre a atividade da empresa, se esta é nociva ao meio ambiente e/ou à comunidade.

Os dados quantitativos, que serão levantados, serão analisados com o auxílio da estatística descritiva "compreende o manejo dos dados para resumi-los ou descrevê-los, sem ir além, isto é, sem procurar inferir qualquer coisa que ultrapasse os próprios dados" (FREUND \& SIMON, 2000). A estatística descritiva ou análise exploratória foca somente em resumir, descrever ou apresentar dados (COLLIS \& HUSSEY, 2005). Os dados qualitativos que serão obtidos por entrevista semiestruturada com a população as adjacências das empresas, serão analisadas também por estatística descritiva e as opiniões dos moradores, por meio do método indutivo, conforme Figura 4. 


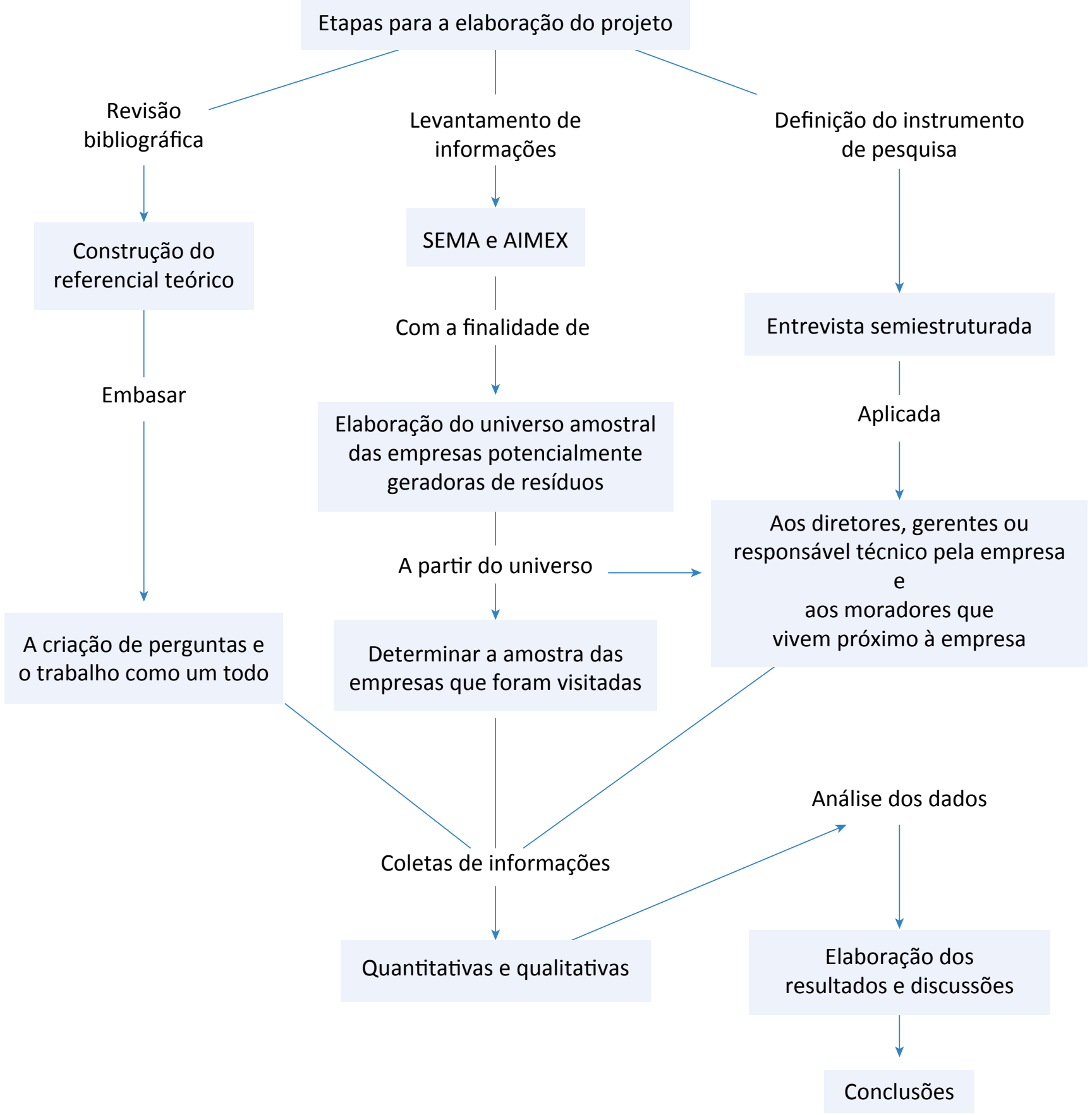

Figura 4 - Metodologia proposta para realização de um diagnóstico socioambiental sobre geração e destinação dos resíduos da indústria madeireira.

\section{CONCLUSÕES}

A indústria madeireira é um importante segmento que gera empregos, rendas e divisas nos países que fazem uso de tal recurso. Gera produtos que auxiliam em ou- tras atividades, como na construção civil, e é uma atividade cuja matéria-prima é retirada de florestas, de modo que, quando não realizada de maneira conscien- 
te, é altamente predatória, gerando inúmeros problemas ambientais e sociais.

Essa indústria apresenta, principalmente na Região Amazônica, um baixo rendimento operacional e, por conseguinte, uma alta geração de resíduos que, caso não dispostos ou aproveitados de maneira correta, trazem problemas ambientais (como a contaminação de rios, solos e ar) e sociais (como problemas respira- tórios, proliferação de vetores de doenças que podem afetar a população ao redor dessas indústrias). O investimento em equipamentos mais eficientes, em mão de obra qualificada e no aproveitamento desses resíduos (seja na forma de reutilização, seja como reciclagem) torna essa atividade sustentável, diminuindo os problemas causados à população e ao ambiente, e proporciona maior credibilidade a esse setor.

\section{REFERÊNCIAS}

ABREU, L. B.; MENDES, L. M.; SILVA, J. R. M. Aproveitamento de resíduos de painéis de madeira gerados pela indústria moveleira na produção de pequenos objetos. Árvore, v. 33, n. 1, p. 171-177, 2009.

ASSOCIAÇÃO BRASILEIRA DE NORMAS TÉCNICAS - ABNT. NBR 10004. Resíduos sólidos: classificação. Rio de Janeiro, 2004.

BATISTA, D. C.; SILVA, J. G. M.; CORTELETTI, R. B. Desempenho de uma serraria com base na eficiência e na amostragem do trabalho. Floresta Ambiente, v. 20, n. 2, jun. 2013.

BRASIL. Lei $n^{\circ} 12.305$, de 2 de agosto de 2010. Dispõe sobre seus princípios, objetivos e instrumentos, bem como sobre as diretrizes relativas à gestão integrada e ao gerenciamento de resíduos sólidos, incluídos os perigosos, às responsabilidades dos geradores e do poder público e aos instrumentos econômicos aplicáveis. Diário Oficial da União, Brasília, 3 ago. 2010.

BRASIL. Ministério do Meio Ambiente. Secretaria de Mudanças Climáticas e Qualidade Ambiental. Projeto PNUD BRA 00/20: Apoio às Políticas Públicas na Área de Gestão e Controle Ambiental. Aproveitamento de resíduos e subprodutos florestais, alternativas tecnológicas e propostas de políticas ao uso de resíduos florestais para fins energéticos. Curitiba, 2009. Disponível em: <http://www.mma.gov.br/estruturas/164/_publicacao/164_publicacao10012011033501.pdf>. Acesso em: 29 out. 2014.

BRITO, L. S.; CUNHA, M. E. T. Reaproveitamento de resíduos da indústria moveleira. Científica Ciência Exatas e Tecnológicas, 2009.

BRUNDTLAND, G. H. (Org.) Nosso futuro comum. Rio de Janeiro: FGV, 1987.

CASSILHA, A. C.; PODLASEK, C. L.; CASAGRANDE JÚNIOR, E. F.; SILVA, M. C.; MENGATTO, S. N. F. Indústria moveleira e resíduos sólidos: considerações para o equilíbrio ambiental. Educação \& Tecnologia, v. 8, p. 209-228, 2004.

CASTRO, E. M. R. de; SILVA, R. N. M. da. Setor madeireiro, dinâmica de atores e política florestal. In: VENTURIERI, A. (Ed.). Zoneamento ecológico-econômico da área de influência da rodovia BR 163 (Cuiabá-Santarém) diagnóstico do meio socioeconômico, jurídico e arqueologia. Belém: Embrapa Amazônia Oriental, 2007. Cap. 8.

CORONEL, D. A.; LAGO, A.; LENGLER, L.; SILVA, T. N. O aproveitamento dos resíduos do setor florestal de Lages - Santa Catarina. In: CONGRESSO DA SOBER, 46., Londrina, 2007. Anais... Londrina, 2008.

FINOTTI, A. R.; SCHNEIDER, V. E.; WANDER, P. R.; HILLIG, E.; SILVA, M. D. A. Uso energético de resíduos de madeira na cadeia produtiva de madeira/móveis e possibilidades de geração de créditos de carbono. In: PÓLO MOVELEIRO DA SERRA GAÚCHA. Sistemas de gerenciamento ambiental na indústria moveleira. São Paulo: Edusp, 2006. 
FONTES, P. J. P. Auto-suficiência energética em serraria de pinus e aproveitamento de resíduos. Curitiba, 1994. $104 f$. Dissertação (Mestrado em Engenharia Florestal) - Setor de Ciências Agrárias, Universidade Federal do Paraná.

FRANCESCHIN, G. L. Biomassa de madeira pode gerar 28 MW de energia. Povos Indígenas no Brasil, 2004. Disponível em: <http://pib. socioambiental.org/c/noticias?id=32081>. Acesso em: 25 jun. 2014.

GOMES, J. I.; SAMPAIO, S. S. Aproveitamento de resíduos de madeira em três empresas madeireiras do Estado do Pará. Comunicado Técnico, Belém, 2004.

HASAN, A. R.; GABRIELE, H. S.; TOWNSEND, T. Online sorting of recovered wood waste by automated XRF-technology: Part II. Sorting efficiencies. Waste Management, p. 695-704, 2011.

JACOBI, P. R.; BESEN, G. R. Solid waste management in São Paulo: the challenges of sustainability. Estudos Avançados, v. 25, n. 71, p. 135-158, 2001.

LEEUWESTEIN, J. M., MONTEIRO, R. A. Procedimento técnico para enquadramento de corpos de água documento orientativo. Brasília: MMA, 2000

LELIS, A. T. (Coord.). Biodeterioração de madeiras em edificações. São Paulo: IPT, 2001.

LENTINI, M.; PEREIRA, D.; CELENTANO, D.; PEREIRA, R. Fatos florestais da Amazônia. Belém: Imazon, 2005. 110 p.

LIMA, E. G.; SILVA, D. A. Resíduos gerados em indústrias de móveis de madeira situadas no polo moveleiro de Arapongas - PR. Floresta, v. 35, n. 1, p. 105-116, 2005.

LOPES, C. S. D. Desenho de pequenos objetos de madeira com resíduo da indústria de processamento mecânico da madeira. Revista de Gestão Integrada em Saúde do Trabalho e Meio Ambiente, v. 4, n. 3, p. 28, 2009.

MENDONZA, Z. M. S. H.; EVANGELISTA, W. V.; ARAÚJO, S. O.; SOUZA, C. C.; RIBEIRO, F. D. L.; SILVA, J. C. Análise dos resíduos madeireiros gerados nas marcenarias do município de Viçosa - Minas Gerais. Árvore, Viçosa, v. 34, n. 4, p. 755-760, 2010.

MONTEIRO, K. F. G.; KERN, D. C.; RUIVO, M. L. P.; RODRIGUES, T. E.; COMETTI, J. L. S. Uso de resíduos de madeira como alternativa de melhorar as condições ambientais em sistema de reflorestamento. Acta Amazonica, Manaus, v. 40, n. 3, set. 2010. Disponível em: <http://www.scielo .br/scielo.php?script=sci_arttext\&pid=S0044$59672010000300001 \& \operatorname{lng}=e n \& n$ rm=iso>. Acesso em: 4 jun. 2014.

NAHUZ, M. A. R. Resíduos da indústria moveleira: a cadeia produtiva de móveis no Brasil. São Paulo: IPT (Divisão de Produtos Florestais), 2005.

NUNES, P. A.; MELO, C. O.; TEIXEIRA, D. A participação do setor madeireiro na economia das microrregiões geográficas do Paraná - 2009. Revista Brasileira de Agropecuária Sustentável, v. 2, n. 1, p. 8-20, jul. 2012.

PEREIRA, D.; SANTOS, D.; VEDOVETO, M.; GUIMARÃES, J.; VERÍSSIMO, A. Fatos florestais da Amazônia 2010. Belém: IMAZON, 2010.

REVEILLEAU, A. C. A. A. Gestão compartilhada de resíduos sólidos e a proteção ambiental: uma abordagem jurídica da responsabilidade socioambiental. Erechim: Habilis, 2008.

REVISTA DA MADEIRA. Produtos para tratar madeira previnem perdas. Revista da Madeira, n. 117, nov. 2008. Disponível em: $<$ http://www.remade.com.br/br/revistadamadeira_materia.php?num=1332\&subject=Preservantes\&title=Produtos\%20 para\%20tratar\%20madeira\%20previnem\%20perdas>. Acesso em: 14 jan. 2015.

RIUL, M.; RIBEIRO, E. L. Diagnóstico e diretrizes para a gestão de resíduos no APL de móveis de João Pessoa-PB. UNOPAR Científica Ciências Exatas e Tecnológicas, Londrina, v. 11, n. 1, p. 15-24, nov. 2012. 
RIVERO, S.; ALMEIDA, O.; ROSÁRIO, L. F.; RODRIGUES, L. F.; AROUCK, J. H. S.; FERNANDEZ, R. D. Instituições, gestão dos recursos naturais e o setor madeireiro no estado do Pará. Amazônia: Ciência \& Desenvolvimento, Belém, v. 7, n. 13, jul./dez. 2011.

RUIVO, M. L. P.; MONTEIRO, K. F. G.; SILVA, R. M.; SILVEIRA, I. M.; QUARESMA, H. D. A. B.; SÁ, L. D. A.; PROST, M. T. R. Gestão florestal e implicações sócio-ambientais na amazônia oriental (estado do Pará). Oecologia Brasiliensis, 2007.

SERVIÇO FLORESTAL BRASILEIRO - SFB; INSTITUTO DO HOMEM E MEIO AMBIENTE DA AMAZÔNIA - IMAZON (Orgs.). A atividade madeireira na Amazônia brasileira: produção, receita e mercados. Belém: SFB; Imazon, 2010.

SILVA, J. L. P. Aproveitamento de resíduos da indústria madeireira para geração de energia elétrica - o caso da empresa B. $K$. Energia Itacoatiara LTDA. no estado do Amazonas. Trabalho de Conclusão de Curso (Especialização em Gestão da Indústria Madeireira e Moveleira) - Departamento de Ciências Florestais da Universidade Federal do Paraná, Curitiba, 2011.

SILVA, J. V. H.; BITTAR, A. P.; SERRA, J. C. V.; ZUKOWISKI JÚNIOR, J. C. Diagnóstico do reaproveitamento de resíduos com potencial energético no município de Palmas-TO. Engenharia Ambiental, Espírito Santo do Pinhal, v. 8, n. 2, p. 226-233, abr./jun. 2011.

SZABÓ JÚNIOR, A. M. Educação ambiental e gestão de resíduos. 2. ed. São Paulo: Rideel, 2010. 118 p.

TEIXEIRA, M. G. Aplicação de conceitos da ecologia industrial para a produção de materiais ecológicos: o exemplo do resíduo de madeira. Dissertação (Mestrado) - Salvador, 2005. Disponível em: <http://teclim.ufba.br/site/material_ online/dissertacoes/dis_marcelo_g_teixeira.pdf>. Acesso em: 18 nov. 2014.

VERÍSSIMO, A.; LIMA, E.; LENTINI, M. Polos madeireiros do estado do Pará. Belém: Imazon, 2002. 75 p.

VIDOR, F. L. R.; PIRES, M. J. R.; DEDAVID, B. A.; MONTANI, P. D. B.; GABIATTI, A. Inspection of Wooden Poles in Electrical Power Distribution Networks in Southern Brazil. IEEE-Institute of Electrical and Electronics Engineers, v. 25, p. 479-484. 2010. Disponível em: <http://ieeexplore.ieee.org/stamp/stamp.jsp?arnumber=5345689>. Acesso em: 16 fev. 2015. 